\begin{tabular}{|c|l|}
\hline Title & Micro- patterning in anodic oxide film on al uminium by laser irradiation \\
\hline Author(s) & Jha, H.; Kikuchi, T.; Sakairi, M.; Takahashi, H. \\
\hline Citation & $\begin{array}{l}\text { Electrochimica A cta, 52(14), 4724.4733 } \\
\text { https://doi.org/40.1016/.electacta.2007.01.008 }\end{array}$ \\
\hline Issue Date & 2007-04-01 \\
\hline Doc URL & http://hdl.handle.net/2115/25156 \\
\hline Type & article(author version) \\
\hline File Information & ECA 52-14.pdf \\
\hline
\end{tabular}

Instructions for use 


\title{
Micro-Patterning in Anodic Oxide Film on Aluminium by Laser Irradiation
}

\author{
H. Jha*, T. Kikuchi, M. Sakairi and H. Takahashi \\ Lab. of Interface Microstructure Analysis, Division of Materials Science \\ Hokkaido University, kita-13 nishi-8, kita-ku, Sapporo 060-8628, Japan.
}

\begin{abstract}
Microstructures such as microchannels and microchambers were fabricated on anodic oxide film of aluminium with laser direct patterning technique. The aluminium substrate covered with porous type anodic oxide film was dyed with organic dyes followed by hydro-thermal treatment. The coloured and pore sealed film shows much higher absorption then as-formed porous film, that makes possible to pattern various types of microstructures on the film by removing the upper part of the film surface by laser irradiation. Structure of the crystallized hydroxide layer on the surface of the anodic oxide film, formed during pore sealing, as well as the partial removal of anodic oxide film from the surface is described. Microstructures with depth lower than $1 \mu \mathrm{m}$ to $27 \mu \mathrm{m}$ were patterned successfully on 16 and $32 \mu \mathrm{m}$ thick anodic oxide film surfaces, using various combinations of laser power and laser scanning speed. The affect of the laser scanning speed and laser power density on the shape of the microstructures is also explained.
\end{abstract}

Keywords: Anodizing, Pore sealing, Laser patterning, Microchannel, $\mu$-TAS, MEMS.

\section{INTRODUCTION}

Patterning is of paramount importance in many areas of modern science and technology. It's applications ranging from the production of integrated circuits, storage devices, display units to fabricate micro electromechanical systems (MEMS), micro-total analysis system ( $\mu$-TAS), and miniaturized sensors [1-3].

Miniaturization plays an important role not only in the electronic industries but also in medical, aerospace, military and other fields. Therefore, in these areas, there is a growing need to develop components and systems with smaller dimensions. Patterning technologies, such as lithographic techniques are one of the well established methods for the fabrication of miniature components. Adaptation of silicon lithography and batch etching processing, initially developed in the semiconductor industry, is the dominant MEMS fabrication method today. In fact, photolithographic techniques are best suitable for large production of identical parts. However, there are many types of miniaturized components, that are not compatible or cost-effective if processed with photolithographic tools. Therefore, the patterning methods other than photolithography, have rising interest in fabricating micro and nanodevices. Other techniques such as direct-patterning techniques may offer unique advantages and superior capabilities for the micro and nano fabrication [4]. For direct patterning without photolithography on flat surfaces, many methods have been reported with simple and more flexible to fabricate micro and nano-structures [5-11]. Recently, Chou et al [5] reports an ultra-fast nano-patterning technique, laser assisted direct imprint (LADI), which is capable to pattern $140 \mathrm{~nm}$ wide and $110 \mathrm{~nm}$ deep grating on silicon. This is an outstanding example of the emerging abilities of direct pattern techniques.

Patterning with a scanning probe microscope (SPM) for the fabrication of nanometre scale structures has been reported by several authors [4, 8-11]. Patterning with atomic force microscopes (AFM) and scanning tunnelling microscopes (STM) with ultra-sharp tips can achieve very high resolution patterns on surface. The process, generally, requires direct contact between the surface of a substrate and a rigid stylus that moves across the surface to scratch a relief pattern [10]. The main disadvantages of these techniques are durability of stylus, and slow processing speed, which makes the mass production difficult.

The use of lasers for direct-write applications offers many advantages for microfabrication. Laser tools are increasingly being used to fabricate miniature components, like in micro electrome- 
chanical systems and prototyping of micro fluidic devices. Some of the present authors, Kikuchi et al. [12-14] reported that complete removal of selected parts of anodic oxide film, from the aluminium substrate by laser irradiation, followed by electrodeposition, and dissolution of the aluminium substrate for the fabrication of well-ordered threedimensional microstructures and printed circuit boards. Recently, the technique is successfully applied for the fabrication of micro-actuators [15], and electrochemical micro-reactors [16]. Similarly, a growing number of companies developing laser micromachining techniques for an extending number of applications is a proof, that the laser micro machining is becoming well-established technique.

The anodic oxide film formed on aluminium, by anodic oxidation of aluminium, is close to leuco-sapphire or glass ceramics, which are widely used in microelectronics. According to Mukhurov et al [17-19] $\gamma$-anodic alumina, prepared in 3\% aqueous solution of oxalic acid, has sufficient mechanical strength and stability in extreme environments that are suitable for the fabrication of hybrid integrated circuits (HIC). Besides, fabrication on anodic oxide film attached to the aluminium substrate adds an extra strength to system and can be useful to design variety of micro-devices and components.

Anodic oxide film on aluminium, prepared in oxalic acid solution, is transparent with light yellow in appearance. Therefore, it is difficult to machine on the anodic oxide film by laser beams, as most of the energy passes through the film. Some recent developments in laser processing have reported that, femto-second lasers are useful to machine transparent materials like ceramic alumina [20]. Some of the present authors M. Sakairi et al [21] reports that, by dyeing, the energy transmitted by laser irradiation is absorbed effectively, more than $85 \%$ of the beam energy, in the oxide film. It has been reported that, during hydrothermal pore sealing, a crystalline hydroxide layer formed over the film surface with a compact intermediate sub layer beneath it. Simultaneously, the pores are filled by the formation of boehmite or pseudoboehmite inside the pores [22-27].

The present research intend to study the effect of colouring and hydrothermal pore-sealing on the absorption properties of the porous anodic oxide film of aluminium. Moreover, carving the coloured and pore-sealed anodic oxide film by removing the upper layers (outer acicular layer and intermediate sub-layer) from the film surface, as well as the fabrication of deep microstructures in the anodic oxide film by ablating the bulk of the film, with the help of laser irradiation.

\section{EXPERIMENTAL METHODS}

\subsection{Specimen/pre-treatment}

Pure aluminium sheet (99.99 wt.\%) with $350 \mu \mathrm{m}$ thickness was used as substrate. The sheet cut into $20 \times 18 \mathrm{~mm}^{2}$ rectangular plates with a narrow handle. The specimens were cleaned with ethyl alcohol in ultrasonic bath for 10 minutes. Then electropolished in 78 vol. $\% \mathrm{CH}_{3} \mathrm{COOH}+22$ vol.\% $\mathrm{HClO}_{4}$ solution for $5 \mathrm{~min}$ at $28 \mathrm{~V}$. The temperature of the electropolishing bath was maintained lower than $283 \mathrm{~K}$. The various steps of the laser assisted micro-patterning in the anodic oxide film on aluminium are summarized in Fig.1.

\subsection{Anodizing}

After pre-treatment, the specimens were anodized in $0.22 \mathrm{M} \mathrm{H}_{2} \mathrm{C}_{2} \mathrm{O}_{4}$ solution with a constant current of $100 \mathrm{Am}^{-2}$ for 3.6 and $7.2 \mathrm{ks}$ to get porous anodic oxide film on the aluminium substrate. Temperature of the anodizing bath was controlled at 293 K

After anodizing, the specimens were immersed in $0.029 \mathrm{M}$ (that is about 1\%) Alizarin red S dyeing solution, for $300 \mathrm{~s}$ at $333 \mathrm{~K}$ to impregnate the dyestuff in the pores of the anodic oxide film. Finally, the specimens were subjected to pore sealing in boiling doubly distilled water for $15 \mathrm{~min}$, unless otherwise described. For the reflectance measurements, $1 \%$ solutions of various dyes were used: Alumilan Black 888, Alizarin Red S, Alumalight Black 555, Alumalight Violet RB and Alumalight Red BL (brand names; KANAME \& Co. Ltd.).

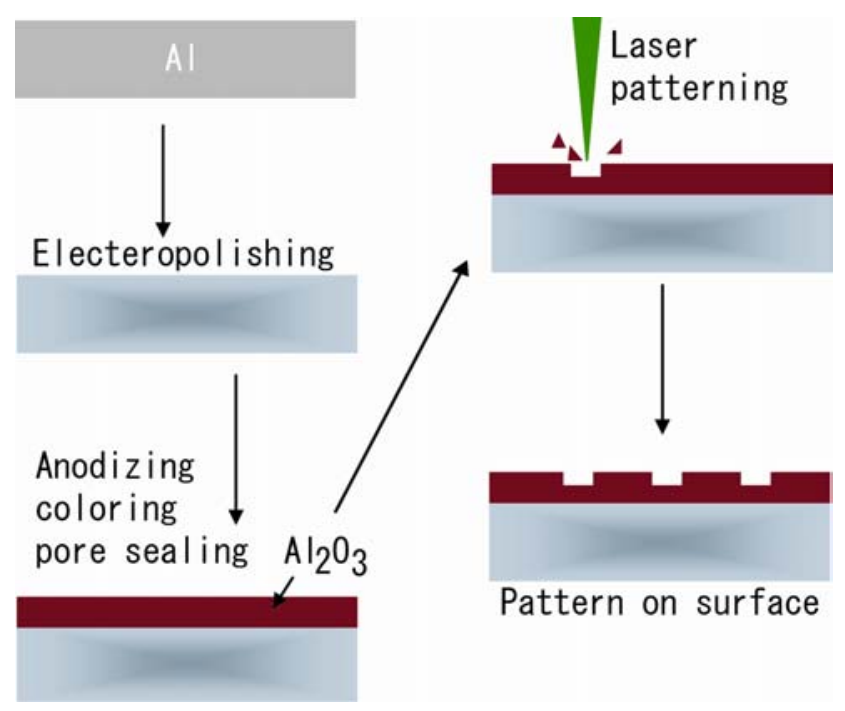

Fig. 1: Schematic diagrams of the process of laser assisted micro patterning in anodic oxide films on aluminium. 


\subsection{Laser Patterning}

The anodic oxide film, formed on the aluminium substrate was irradiated with a Q-switched, second harmonic, pulse Nd:YAG laser (Spectra Physics; GCR-100 series) with $532 \mathrm{~nm}$ wavelength, $8 \mathrm{~ns}$ pulse width, and $50 \mathrm{~Hz}$ frequency. The laser has Gaussian type propagation, that is, the beam electric field and intensity follow Gaussian distribution. The laser beam diameter at $1 / \mathrm{e}^{2}$ was about 7.8 $\mathrm{mm}$. The laser beam intensity was reduced by a splitter. Before projecting the laser beam by a convex lens, the beam was passed through a rectangular diaphragm, to obtain a rectangular shaped beam. The laser irradiation was carried out inside a plastic cell filled with doubly distilled water. There was a quartz window in the cell for the passage of laser beam, as shown in Fig. 2.

The power density of the irradiated laser beam was from $62 \mathrm{~mW} / \mathrm{cm}^{2}$ to $160 \mathrm{~mW} / \mathrm{cm}^{2}$, measured by a laser power measurement head (Ophir; 12A-P-SH) connected with a digital meter (NOVAII, Ophir optronics). Measurement of laser power density was carried out between the diaphragm and projection lens, just before the laser irradiation. The speed of the 3D movable stage (KOHZU; PK 569B) was varied from $10 \mu \mathrm{m} / \mathrm{s}$ to $60 \mu \mathrm{m} / \mathrm{s}$ in two dimensions, which was controlled by a computer with an accuracy of fractions of a micrometer. Similarly, the distance between lens and the specimen was $66 \pm 1 \mathrm{~mm}$ (because of the beam refraction with the quartz window and water inside the cell, the focus point shifted from $60 \mathrm{~mm}$ ). At the focal point, the rectangular shape of the beam vanished, and the beam was almost circular, so, to retain the rectangular characteristics the specimen was defocused from the focus point by up to $1 \mathrm{~mm}$.

\subsection{Analysis}

The percentage reflectance of the as formed, pore sealed, as well as the coloured and pore sealed anodic oxide film attached to the aluminium substrate was observed by a scanning spectrophotometer (Shimadzu; UV-3100PC, UV-VISNIR). The microstructures on the anodic oxide film on the aluminium were analysed by a confocal scanning laser microscope, CSLM (Lasertec, 1LM21D) and a field emission scanning electron microscope, FE-SEM (JEOL, JSM-6500F). For cross-sectional observations in FE-SEM, the film along with the aluminium substrate was subjected to tensile fracture. An additional analysis was carried out using GD-OES and EDS to measure the distribution of dyestuff inside the film.

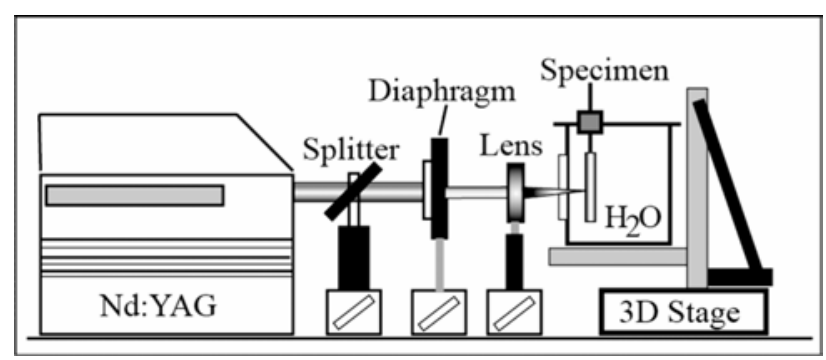

Fig. 2: Diagrammatic representation of the laser irradiation setup to pattern anodic oxide film on aluminium.

\section{RESULTS AND DISCUSSION}

\subsection{Structure of the outer part of the oxide film after pore sealing}

Sealing of porous anodic oxide film on aluminium in boiling doubly distilled water forms an acicular crystalline hydroxide layer on the outer film surface. Also, a compact and continuous intermediate layer forms immediately below the acicular surface layer.

Figure 3 (a to d) shows FE-SEM images of anodic oxide films formed on aluminium substrate. In Fig. 3 (a), the FE-SEM image is a cross-sectional view of a coloured and pore sealed film, where many fine parallel lines in the porous layer can be observed. Cross-sectional image of the film surface, Fig. 3 (b), shows a bright layer, of about $1 \mu \mathrm{m}$ thickness, at the film surface. Beneath the bright layer, filled-porous layer extends towards the filmsubstrate interface. The further magnification in Fig. 3 (c), shows the bright layer is differentiated into a loosely arranged outer acicular layer, and a continuous intermediate sub-layer just beneath the acicular layer. The thickness of the acicular layer is about 300 to $400 \mathrm{~nm}$ whereas the intermediate layer is about $600-700 \mathrm{~nm}$, after $30 \mathrm{~min}$ of pore sealing. Figure 3 (d) shows the surface view of a crater on the film, which was obtained after irradiating low energy laser beam on the surface of the coloured and pore sealed anodic oxide film. The figure clearly shows, successively, the morphology of the acicular hydroxide layer and a part of intermediate layer.

The oxide film formed by anodizing of aluminium in oxalic acid solution consists of many fine hexagonal cells upright to the metal substrate. The cells have a pore at the centre of the each cell, which extends to the metal-film interface, and forms the porous layer on the substrate. Fine lines stretching through this layer can be seen also after colouring and pore sealing, as shown in Fig. 3(a). The po 

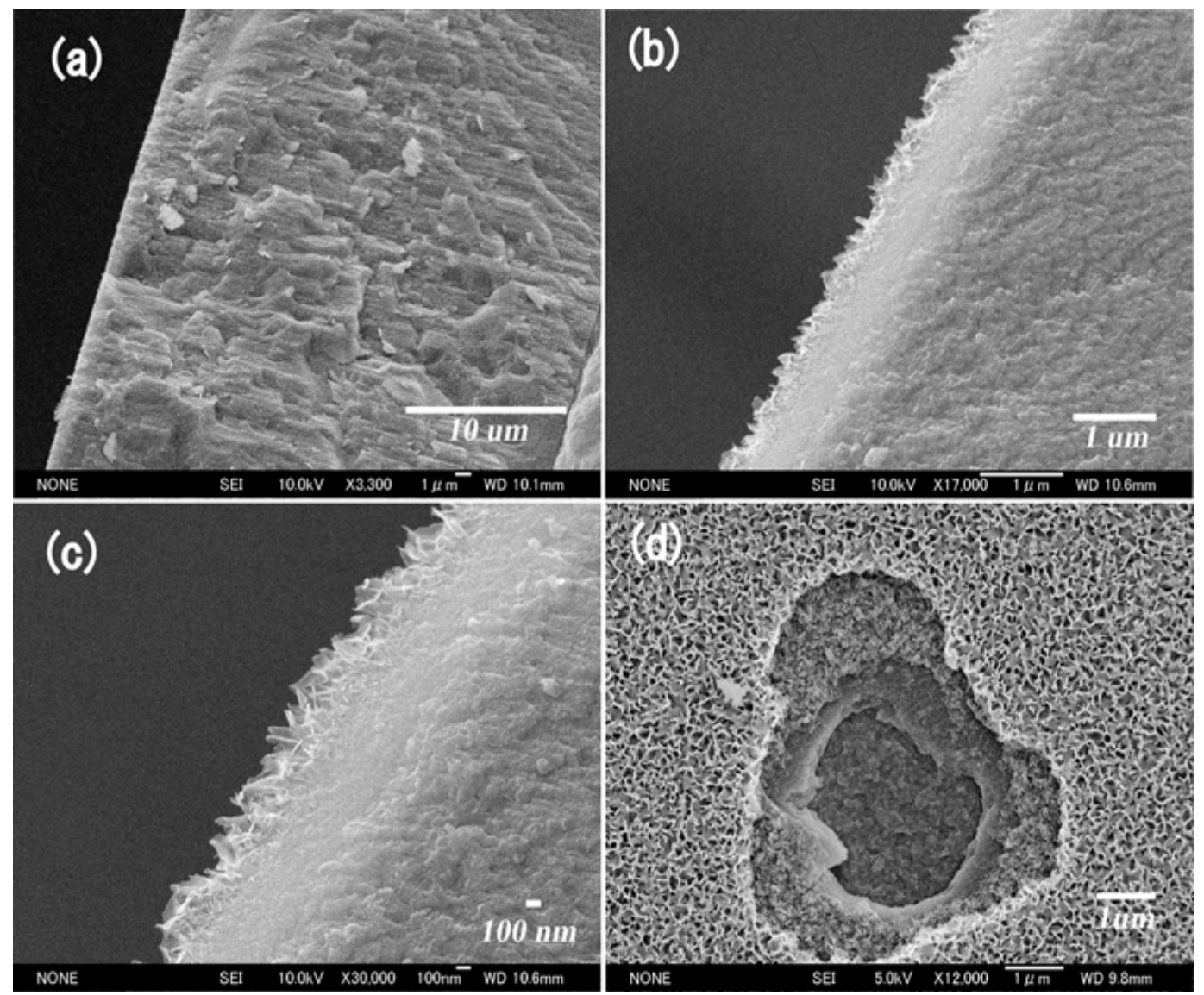

Fig. 3: Cross-sectional views of anodic oxide film formed by $2 \mathrm{~h}$ of anodizing and colouring followed by pore sealing for 30 min. (a) FE-SEM image of film on the aluminium substrate; (b-c) magnified FE-SEM images showing porous bulk oxide and surface layers. (d) FE-SEM image of the surface of the crystalline hydroxide, showing the gradual decrease in crystallization towards the bulk film.

rous layer is separated from the metal substrate by a thin hemispherical barrier layer at the interface between the oxide film and the metal substrate [22]. The thickness of the film, after pore sealing, was found to be 16 and $32 \mu \mathrm{m}$ after anodizing for 1 and 2 $\mathrm{h}$ respectively. For the pore sealing, it is reported that, about $10 \mathrm{~min}$ treatment, with doubly distilled water, is sufficient to seal the pores. Afterwards, water penetration across the hydroxide layer is slow, but allows the further progress of hydration. The structure of the pore sealed film and the mechanisms for the pore sealing are already explained in several articles [23-27]. During the plugging of the pores, it believes that, the formation of crystalline boehmite or pseudoboehmite, with the acicular structure on the surface, is because of dissolution and precipitation of anhydrous oxide film. During the pore sealing, water passes inside the pores and this cause to dissolve anhydrous oxide from the pore walls, forming aquo-hydroxo complexes, that on saturation precipitate and results in the plugging of the pores, as well as formation of the acicular crystalline hydroxide layer on the film surface.
Similarly, a continuous and compact intermediate layer formed, just beneath the outer acicular layer, by water penetrating through the outer crystalline hydroxide layer shown in Fig. 3 (b and c). The reaction front with penetrating water moves towards the metal at the base, and crystalline boehmite progressively formed towards the external surface, can be seen in Fig. 3(d).

\subsection{Change of absorption by colouring and pore sealing of the anodic oxide film}

The porous anodic oxide film on the aluminium, prepared in oxalic acid solution, is transparent and has light yellow appearance. Dyeing the porous film by organic dyes followed by pore sealing in boiling water, strongly enhances the absorption properties of the film.

Figure 4 (a) shows the variation in reflectance of a $32 \mu \mathrm{m}$ thick anodic oxide film on aluminium substrate with wavelength. Here the curve A stand for the as-formed porous anodic oxide film on substrate and shows that the reflectance varies from about 30 to $15 \%$ in the 400 to $800 \mathrm{~nm}$ wavelength 

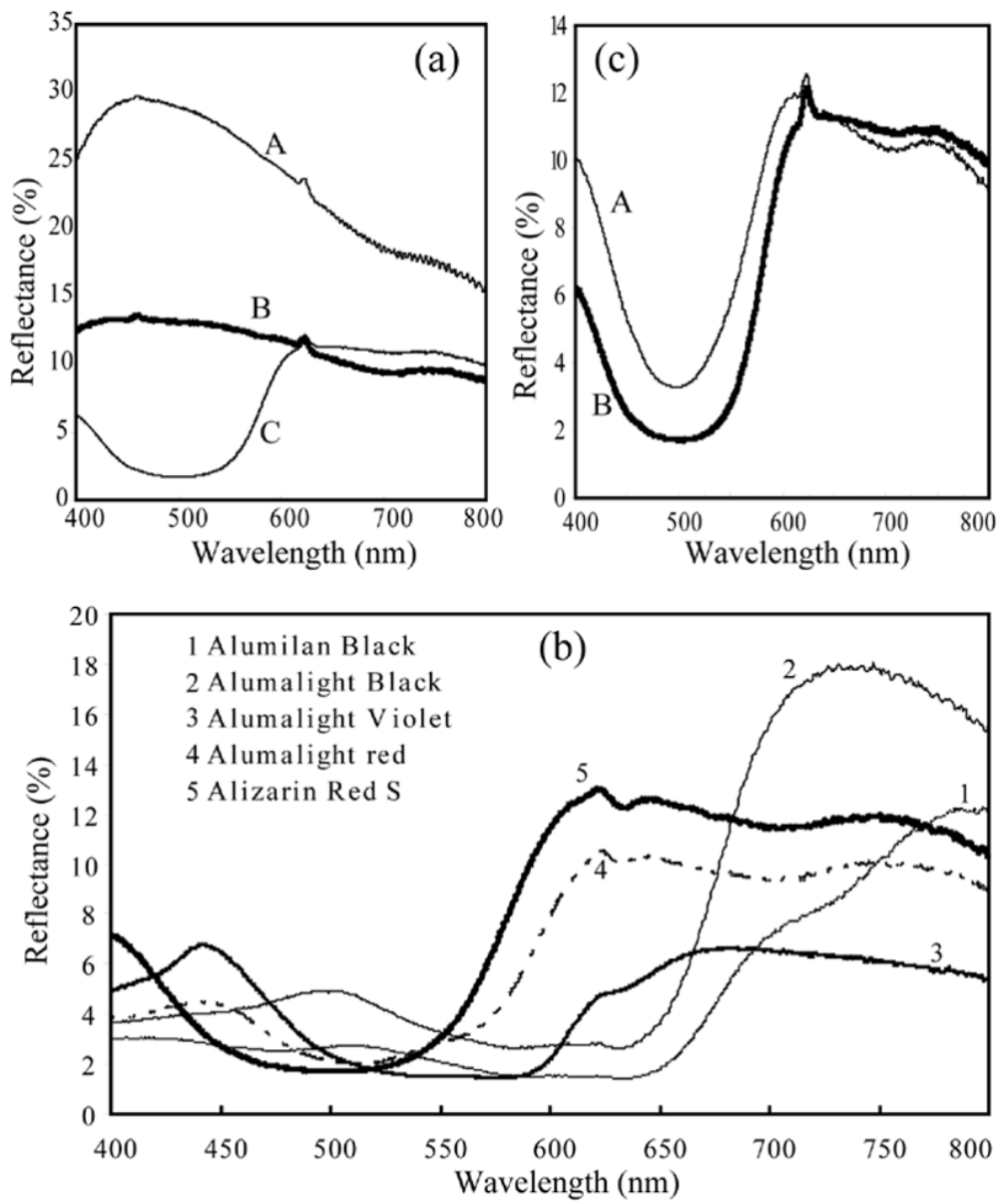

Fig. 4: (a). Percentage of reflectance spectra for the $32 \mu \mathrm{m}$ thick film on aluminium substrate. (A) porous anodic oxide film as prepared; (B) after pore sealing treatment in boiling water for $15 \mathrm{~min}$; (C) after colouring with $0.029 \mathrm{M}$ alizarin red followed by pore sealing in boiling water for $15 \mathrm{~min}$. (b) Percentage of reflectance of films treated with different dyes. (c). Percentage of reflectance observed after colouring with $0.029 \mathrm{M}$ alizarin red solution followed by pore sealing in water for 15 minutes for $16 \mu \mathrm{m}$ thick anodic oxide film (A); and (B) for a $32 \mu \mathrm{m}$ thick anodic oxide film.

region. The curve shows, especially, high reflectance in the visible light region, 400 to $650 \mathrm{~nm}$. Curve B was measured after pore sealing of the anodic oxide film (without colouring) in boiling doubly distilled water for $15 \mathrm{~min}$, and the reflectance is significantly lower from 400 to $800 \mathrm{~nm}$. Similarly, curve $\mathrm{C}$ shows the reflectance for a specimen after colouring with Alizarin red S solution followed by pore sealing and indicates that, the film has high absorption in the visible region. Figure 4 (b) shows the reflectance of a $32 \mu \mathrm{m}$ thick film, after colouring with $1 \%$ solutions of various dyes under the same conditions followed by pore sealing for 15 min. Furthermore, Fig. 4 (c) shows the changes in reflectance of 16 (curve A) and $32 \mu \mathrm{m}$ (curve B) thick films after colouring with Alizarin red S solution followed by pore sealing, in same conditions. The $32 \mu \mathrm{m}$ thick film shows higher absorption from $400 \mathrm{~nm}$ to about $625 \mathrm{~nm}$ range, and at $532 \mathrm{~nm}$ the $32 \mu \mathrm{m}$ film has more than twice higher absorption than $16 \mu \mathrm{m}$ thick film.
After the pore sealing, the film develops an acicular boehmite layer and an intermediate layer on the surface of the film, as well as the pores are filled with pseudoboehmite. This changed structural feature inside and on the surface of the film leads to an intense increase in absorption. By sealing the pores, alone, the reflectance of the film drops to $46 \%$ at the $532 \mathrm{~nm}$ wavelength, when compared with as formed porous film, as shown by curves A and B in Fig. 4 (a). Moreover, colouring of the film with organic dyes, like Alizarin red S and the other dyes, before pore sealing, further decreases the reflectance by the film, because of a strong absorption in the visible region, as shown by curve $\mathrm{C}$ in Fig. 4 (a). The results with the different organic dyes in Fig. 4 (b) shows that all absorb strongly in the visible or near visible region and that Alumalight violet has lowest reflectance at $532 \mathrm{~nm}$ (wavelength of the $\mathrm{Nd}: Y A G$ second harmonic). However, adsorption of dyestuff was not uniform when using Alumalight violet and Alumalight red, thus, Alizarin red S of- 

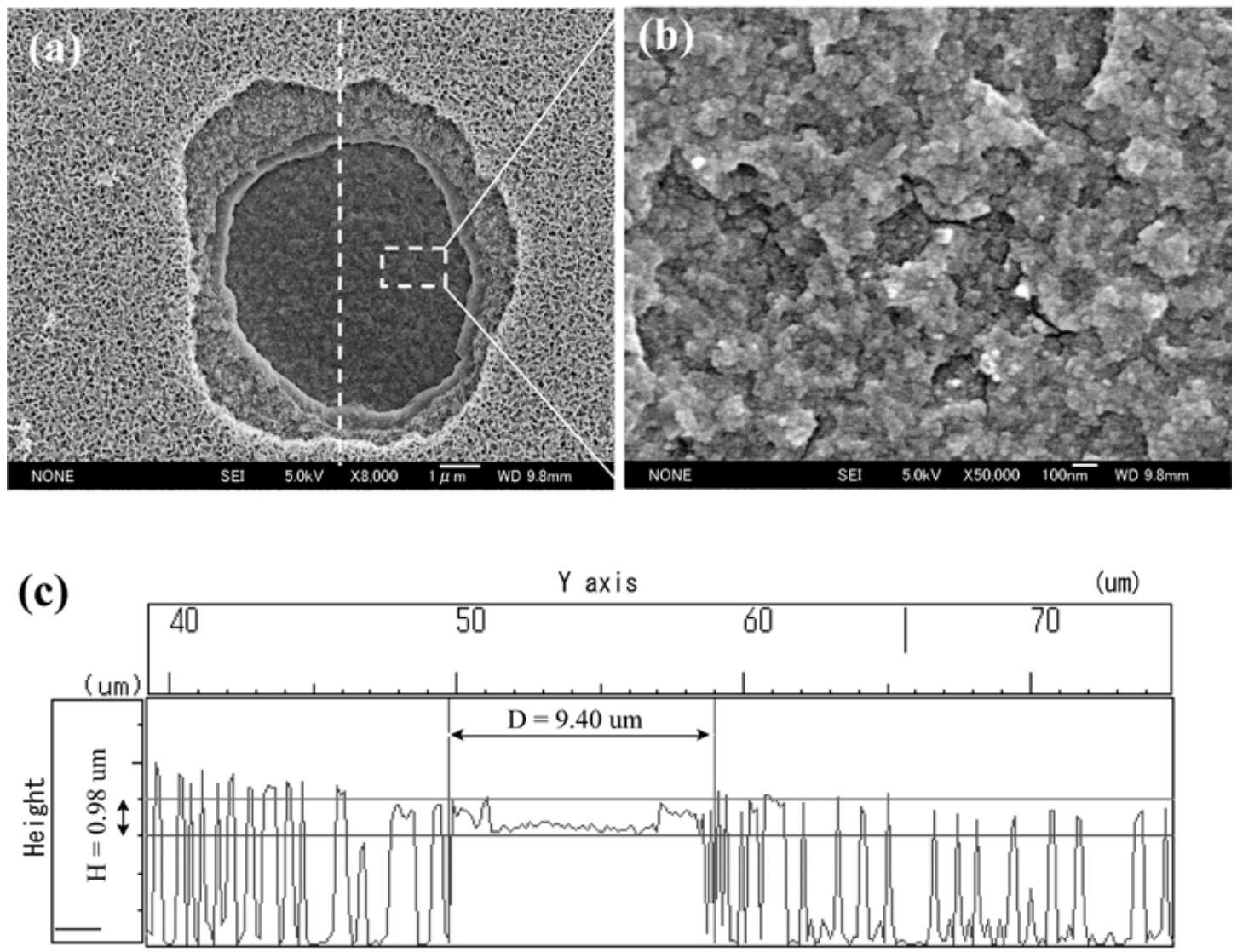

Fig. 5: FE-SEM images and CSLM depth profile of the laser irradiated part of anodic oxide film on aluminium, formed after irradiating 25 pulses of $85 \mathrm{~mW} / \mathrm{cm}^{2}$ laser power density (a) the layers of anodic oxide film removed by the laser beam. (b) Magnification of the bottom of the area where film was removed, and (c) depth profile of the laser irradiated part of (a), along the dashed line.

fers the better colouring of the porous anodic film to enhance the absorption. Measurements by GD-OES and EDS show that, the dye, Alizarin Red S, distribute throughout the film depth. However, the concentration of dye found higher towards the surface, especially beneath the intermediate compact layer. Likewise, it is obvious that the thickness of the oxide film on the aluminium substrate plays an important role in the absorption of the film. As the thickness of the oxide film increases, the absorption by the film also improve significantly.

\subsection{Laser assisted micro-patterning on aluminium supported anodic Oxide films}

Irradiation of low power laser beam on anodic oxide film of aluminium, by focusing through a lens, is sufficient to remove the laser irradiated parts from the film surface.

Figure 5 shows FE-SEM images and a CSLM depth profile of the laser irradiated part on the surface of a $16 \mu \mathrm{m}$ thick anodic oxide film, after depositing 25 pulses of $85 \mathrm{~mW} / \mathrm{cm}^{2}$ laser beam. Here, the laser beam was passed through a circular diaphragm, with an aperture diameter of $10 \mathrm{~mm}$, before projecting by a lens. At the laser irradiated surface, a crater of about $10 \mu \mathrm{m}$ in diameter was formed, as shown in Fig. 5(a). The figure shows the surface of the film is removed in layer manner, and the inner part of the laser irradiated surface shows bulk anodic oxide film, as in Fig. 5(b). The CSLM depth profile of the crater, Fig. 5(c), shows the depth of the crater is less than $1 \mu \mathrm{m}$. Similarly, Fig. 6 shows CSLM images of the laser irradiated part of a $32 \mu \mathrm{m}$ thick film surface, after depositing 25 pulses of $125 \mathrm{~mW} / \mathrm{cm}^{2}$ laser beam. Here, the depth of the 'hole' on the film surface is found about $16.1 \mu \mathrm{m}$, and the diameter is about $20 \mu \mathrm{m}$ as shown by Fig. 6 (b).

Figure 7 (a) shows the CSLM image of microchannels patterned on $16 \mu \mathrm{m}$ thick anodic oxide film, using $62 \mathrm{~mW} / \mathrm{cm}^{2}$ laser beam with $20 \mu \mathrm{m} / \mathrm{s}$ scanning speed. Rough but uniform laser ablated area is clearly seen over the film surface, with good edge definition. Furthermore, variation in the depth of the channels with laser scanning speeds, at 62 and $100 \mathrm{~mW} / \mathrm{cm}^{2}$ laser powers, are plotted in Fig. 7 


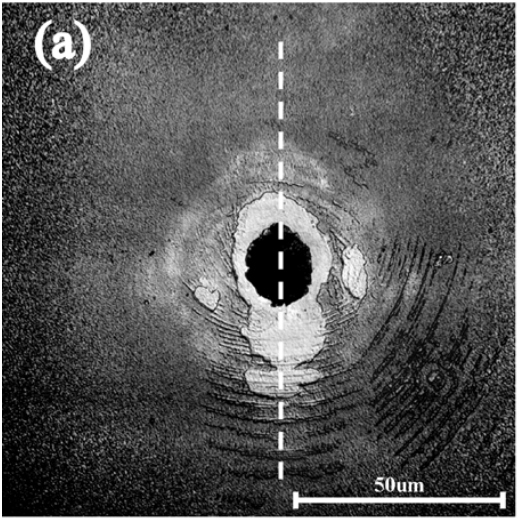

(b)

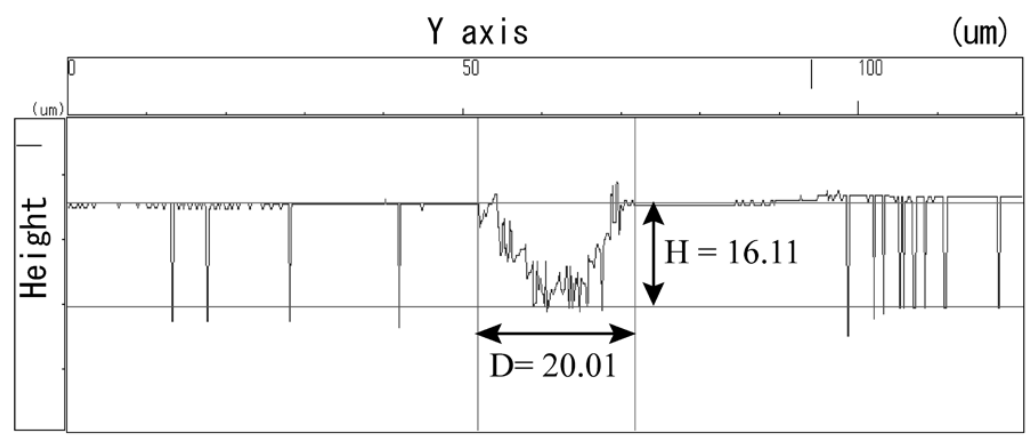

Fig. 6: CSLM image of the laser irradiated part of a $32 \mu \mathrm{m}$ thick anodic oxide film on aluminium, formed by 25 pulses of $125 \mathrm{~mW} / \mathrm{cm}^{2}$ laser power density. (a) Surface image of the anodic oxide film irradiated (removed) by the laser beam. (b) Depth profile of the laser irradiated part of (a), along the dashed line, showing the depth of removed oxide of about $16.1 \mu \mathrm{m}$.

(b). Here, the depth of a channel decreases as the scanning speed increase, but, remain unchanged after around 20 and $30 \mu \mathrm{m} / \mathrm{s}$ for 62 and $100 \mathrm{~mW} / \mathrm{cm}^{2}$ laser beam respectively. However, the depth slightly increases with the higher laser power density, when the scanning speed was low.

Figure 8 (a) shows a CSLM image of microchannels patterned on a $32 \mu \mathrm{m}$ thick film, by using $125 \mathrm{~mW} / \mathrm{cm}^{2}$ laser beam with different scanning speeds. Channel "1" was patterned with the speed of $10 \mu \mathrm{m} / \mathrm{s}$, channel " 2 " with $20 \mu \mathrm{m} / \mathrm{s}$, channel " 3 " with $40 \mu \mathrm{m} / \mathrm{s}$ and channel "4" with $60 \mu \mathrm{m} / \mathrm{s}$. The outer acicular layer was irregularly detached from the film surface, along the sides of the channel. Figure 8 (b) shows the depth of the channels, which decreases gradually from channel " 1 " to " 4 ", pointing out the influence of the laser scanning speeds on depth. Based on several observations with different scanning speeds and laser power densities, the average variation in depth with scanning speed is plotted in Fig. 8(c). Like $16 \mu \mathrm{m}$ thick film, the depth decreases with increasing laser scanning speed. Also, the depth increases with increasing laser power density.

Figure 9 shows CSLM image of crosssection of a microchannel, patterned on $32 \mu \mathrm{m}$ thick anodic oxide film with $125 \mathrm{~mW} / \mathrm{cm}^{2}$ laser beam and $20 \mu \mathrm{m} / \mathrm{s}$ scanning-speed. The cross-section shows, channel has nearly U-shape with a damage at the film-substrate interface, just below the channel.

In almost all cases, it found that, the removal of the oxide film, by laser beam, takes place in layer manner, at least for the upper $1 \mu \mathrm{m}$ thickness from the surface, as shown in Fig. 5 (a). Here, the outer acicular layer and intermediate sub-layer show various layers within $1 \mu \mathrm{m}$ depth of the laser irradiated surface. The layers formed at the laser irradiated surface may be because of Gaussian form of the laser beam. In such laser beam, the power principally concentrated within a narrow cylinder,
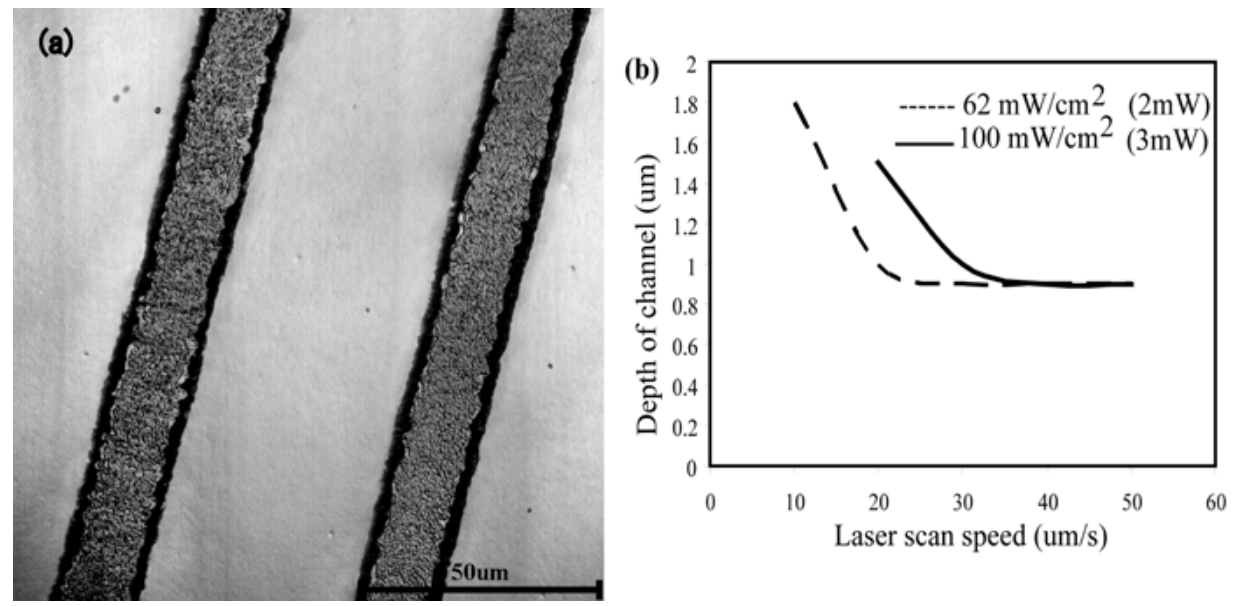

Fig. 7: (a) CSLM image of microchannels patterned on $16 \mu \mathrm{m}$ thick anodic oxide film of aluminium using a $62 \mathrm{~mW} /$ $\mathrm{cm}^{2}$ laser power density and a $20 \mu \mathrm{m} / \mathrm{s}$ laser scanning speed. (b) Average variation in depth of microstructures patterned on $16 \mu \mathrm{m}$ thick anodic oxide film with the laser scanning speed at $62 \mathrm{~mW} / \mathrm{cm}^{2}$ or $100 \mathrm{~mW} / \mathrm{cm}^{2}$. 

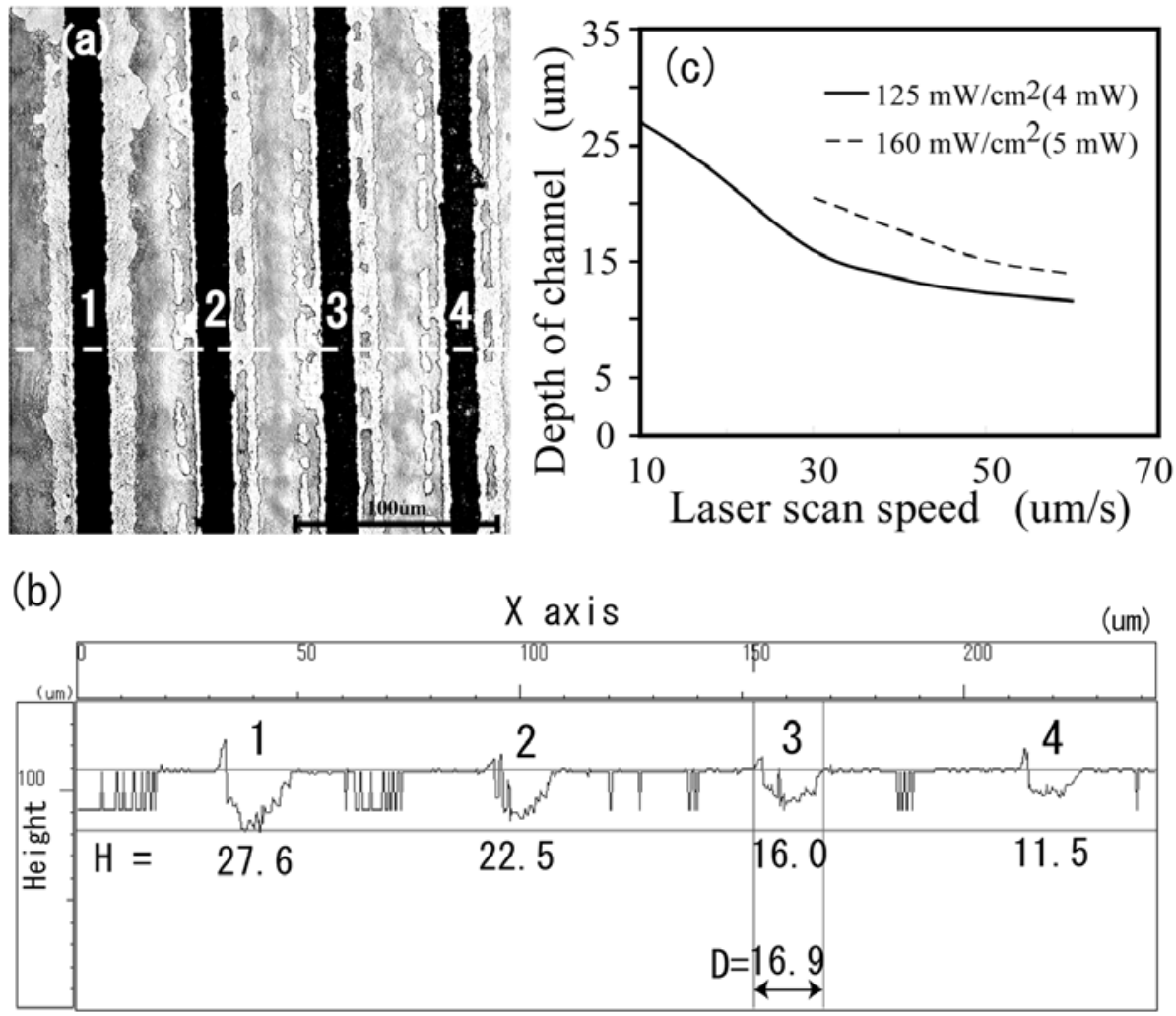

Fig. 8: (a) CSLM image of microchannels patterned on $32 \mu \mathrm{m}$ thick anodic oxide film with a $125 \mathrm{~mW} / \mathrm{cm}^{2}$ laser beam at different scanning speeds; channels 1,2,3 and 4 patterned with 10, 20, 40 and $60 \mu \mathrm{m} / \mathrm{s}$ respectively. (b) Corresponding depths of the channels of Fig. 8 (a). (c) Average variation in the depth of the microstructures (channels) formed on the $32 \mu \mathrm{m}$ thick anodic oxide film with the laser scanning speed at 125 and $160 \mathrm{~mW} / \mathrm{cm}^{2}$ laser power densities. (Note: the apparent holes between the channels are artefacts obtained for the light reflection from the film-metal interface due to the un-even coating of platinum, see $[28,29])$.

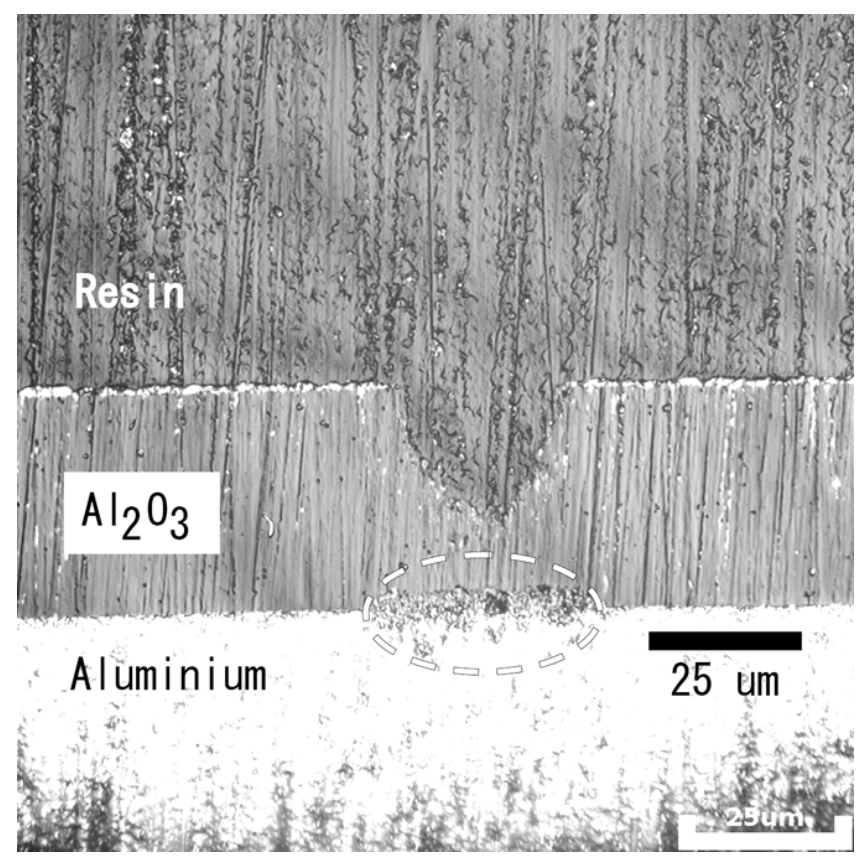

Fig. 9: CSLM image of a cross-section of a microchannel patterned on anodic oxide film on aluminium using a laser power density of $125 \mathrm{~mW} / \mathrm{cm}^{2}$ with a scanning speed of $20 \mu \mathrm{m} / \mathrm{s}$. The broken oval shows damage at the filmsubstrate interface underneath the channel. surrounding the beam axis, and decreases sharply with increasing distance from the axis. The part of the laser beam which has the higher power, penetrates deeper inside the film than the other part of the beam. This unevenness can be reduced by shaping the beam with a small aperture. Also, the morphology of inner part of the oxide film resembles the bulk film inside an intermediate layer, as already shown in Fig. 3 (c and d). Using low laser power beam, below $100 \mathrm{~mW} / \mathrm{cm}^{2}$, the microstructure on the film surface formed mostly because of the removal of outer acicular layer and the intermediate sub-layer. Resulting about $1-1.2 \mu \mathrm{m}$ depth of the microstructure on the surface. These layers remove easily, even with a single pulse of $62 \mathrm{~mW} /$ $\mathrm{cm}^{2}$ laser beam. While increasing the number of pulses (up to 25 pulses), increase the diameter of the removed area. Further increases in the number of pulses formed a narrow and shallow hole at the centre of irradiated surface. However, deeper and wider holes can be obtained by irradiating of larger number of laser pulses or using higher power beam. The diameters and depths of the holes found propor- 

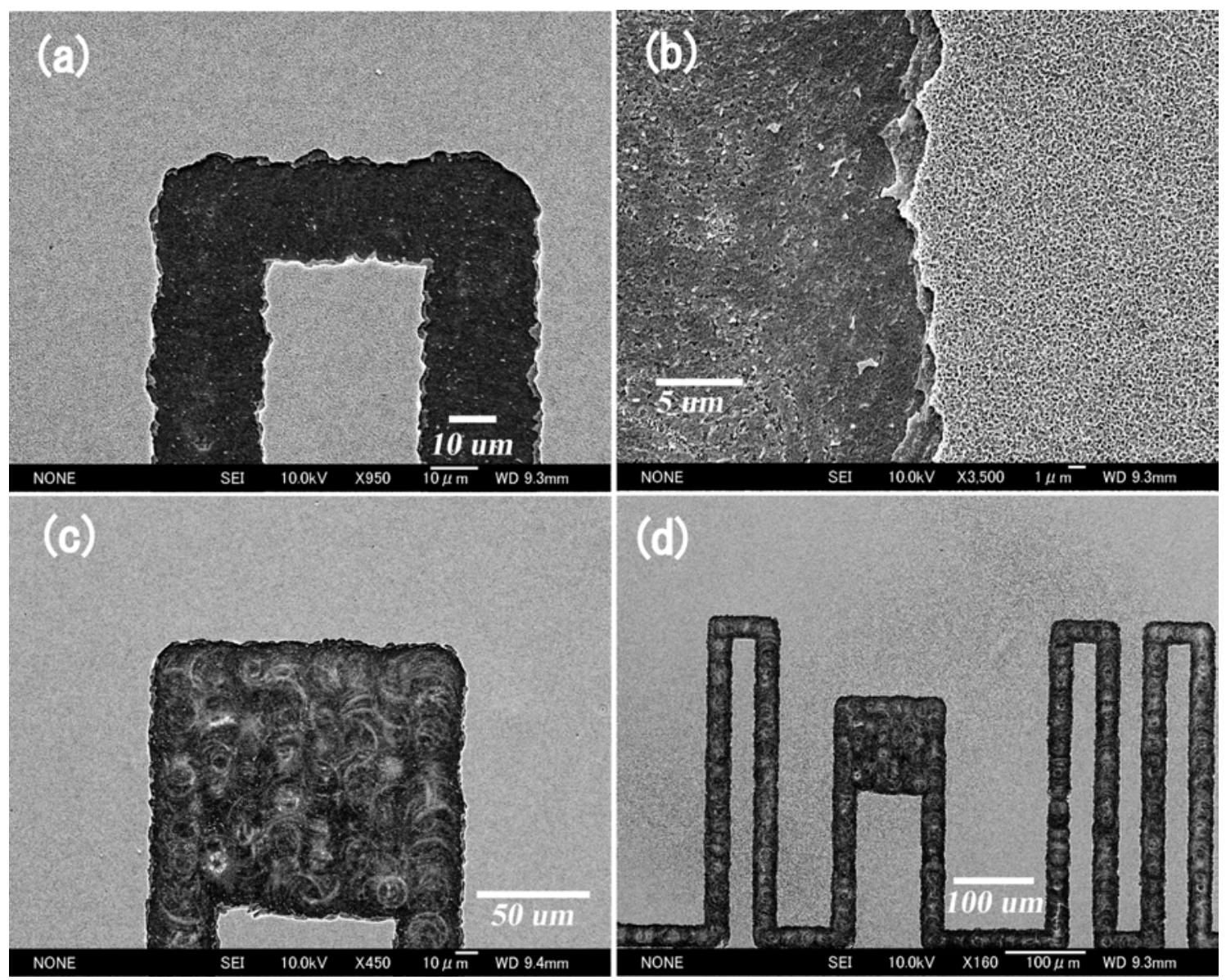

Fig. 10. Scanning electron microscope images of various types of micro-structures patterned on $16 \mu \mathrm{m}$ thick anodic oxide film on aluminium; (a) a section of a $25 \mu \mathrm{m}$ wide microchannel with about $1 \mu \mathrm{m}$ depth, patterned using $62 \mathrm{~mW} /$ $\mathrm{cm}^{2}$ laser beam with $20 \mu \mathrm{m} / \mathrm{s}$ scan speed; (b) magnified view of the laser irradiated part and the film surface, showing that the upper surface of the film is removed in a layered manner and the ablated surface is smooth ; (c) and (d) approx. $1.2 \mu \mathrm{m}$ deep microchamber connected with microchannels patterned by $85 \mathrm{~mW} / \mathrm{cm}^{2}$ laser beam with $20 \mu \mathrm{m} / \mathrm{s}$ scanning speed.

tional to the number of pulses and the laser power density.

Different types of microstructures on the film can be patterned by scanning the laser beam on the film surface. It was found that the rectangular shaped beam, obtained by using a rectangular diaphragm, is ideal to pattern microstructures with good edge definition and shapes. The depth increased with lower scanning speed and higher laser power density is because of the deposition of higher amount of energy at the irradiated surface. The high amount of energy facilitates to remove larger amounts of material from the irradiated film surface.

Patterning on $16 \mu \mathrm{m}$ thick film with laser beam higher than $100 \mathrm{~mW} / \mathrm{cm}^{2}$, completely removed the film from the aluminium substrate. However, the laser scan speed may be increased to overcome the higher power beam, but mostly it results in irregular shape with some deep patches in the pattern. Here laser power densities equal to or less than $100 \mathrm{~mW} / \mathrm{cm}^{2}$ with optimum scanning speeds, as plotted in Fig. 7(b), found suitable to pattern on the anodic oxide film. The depth of the microstructures, on $16 \mu \mathrm{m}$ thick film, limited to about a micrometer or less, because the low power beam is not sufficient to remove the bulk film, under the intermediate sub-layer. Moreover, it found that, increasing the thickness of the anodic oxide film permits to increase the patterning power density of laser beam. Here, the thicker film absorbed a higher fraction of the laser beam at $532 \mathrm{~nm}$ wavelength, as shown in Fig. 4 (c). Because of the high absorption and higher patterning power density, deeper microstructures can be realized on the film surface. Deep microchannels, up to about $27 \mu \mathrm{m}$, were successfully patterned on $32 \mu \mathrm{m}$ thick film using $125 \mathrm{~mW} / \mathrm{cm}^{2}$ laser beam, as in Fig. 8 (a). The inner part of the channels appears dark because of the high depression with rough surface. Like in the $16 \mu \mathrm{m}$ thick 


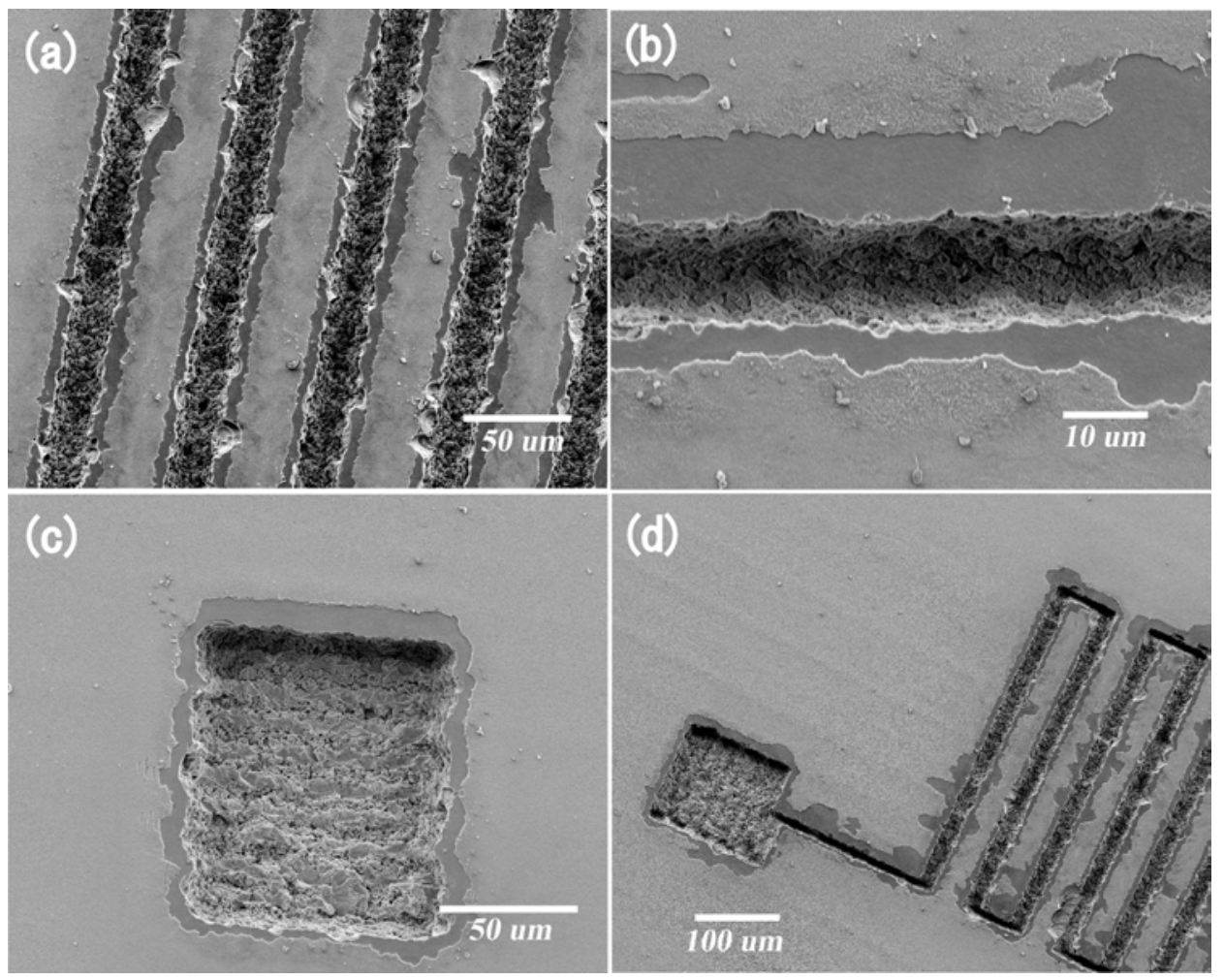

Fig. 11: Scanning electron microscope images of various microstructures patterned on $32 \mu \mathrm{m}$ thick anodic oxide film on aluminium by using a $125 \mathrm{~mW} / \mathrm{cm}^{2}$ laser power density with $30 \mu \mathrm{m} / \mathrm{s}$ of scan speed. (a) Microchannels at regular intervals; (b) magnified view of a microchannel; (c) a microchamber and (d) a microchamber connected with a microchannel. All the structures have 12-15 $\mu \mathrm{m}$ depth with uneven inner surfaces.

film, here also, the laser scanning speed plays a key role in the patterning with different depths as shown in Fig. 8 ( $a$ and $b$ ). For patterning on $32 \mu \mathrm{m}$ thick film, laser beam up to $160 \mathrm{~mW} / \mathrm{cm}^{2}$ can be conveniently used. Observations show that, laser power density higher than $100 \mathrm{~mW} / \mathrm{cm}^{2}$ with moderate scanning speeds, that is 20 to $60 \mu \mathrm{m} / \mathrm{s}$, found optimum to get deep patterns, as in Fig. 8 (c), with good shape. Whereas, the lower power laser beam formed the structure similar to that on $16 \mu \mathrm{m}$ thick film.

The shape of the pattern is, mostly, determined by the properties of the irradiated laser beam. Therefore, Gaussian distribution of the laser beam shows it's influence on cross-sectional shape of the channel, as shown in Fig. 9. It was found that, even after colouring and pore sealing of the film, a fraction of the laser beam passes to the film-substrate interface. Thus, causing heat-up or even melting and re-solidification of the aluminium substrate at the interface. This damage was negligible when using low laser power beam or higher scanning speeds.

\subsection{Fabrication of microchannels and microcham- bers on anodic oxide film of aluminium}

Microstructures, like microchannels and microchambers, were fabricated on anodic oxide film, by using proper combinations of laser power density and laser scanning speed.

Figure 10 shows the microstructures, fabricated on $16 \mu \mathrm{m}$ thick anodic oxide film on aluminium. Fig. 10(a) is a magnified view of a microchannel, fabricated with $62 \mathrm{~mW} / \mathrm{cm}^{2}$ laser beam and $20 \mu \mathrm{m} / \mathrm{s}$ scanning speed. Here, width of the channels is about $25 \mu \mathrm{m}$ and depth is about $1 \mu \mathrm{m}$. The figure shows that the acicular layer, along with the intermediate layer is precisely removed, from the surface of the film, can be seen in Fig. 10 (b). Similarly, an about $1.2 \mu \mathrm{m}$ deep microchamber, Fig. 10(c), was fabricated on the film surface, with $85 \mathrm{~mW} / \mathrm{cm}^{2}$ laser beam and $20 \mu \mathrm{m}$ scanning speed. Long, uniform microstructure, by connecting the microchamber with microchannels, can also be patterned on the film surface, as shown in Fig. 10 (d). These microstructures, with smooth and uniform inner surfaces and well-defined shapes, may be ideal to design various micro fluidic systems and analytical microdevices.

Moreover, deeper microstructures, 12$15 \mu \mathrm{m}$, were patterned on $32 \mu \mathrm{m}$ thick film using higher laser power beam as shown in Fig. 11. Various microchannels at regular intervals were fabri- 
cated with rougher inner surfaces than in Fig. 10, as shown in Fig. 11 (a). Figure 11 (b) is a magnified view of a $12 \mu \mathrm{m}$ wide and about $15 \mu \mathrm{m}$ deep channel. The channels has good edge definition with uniform inner surface. Similarly, an about $15 \mu \mathrm{m}$ deep microchamber was patterned on the film, as in Fig. 11 (c). Also, several deep microstructures were also fabricated on the film, as in Fig. 11 (d), where microchannel is connected with microchamber. However, in almost all cases, the acicular layer on the film surface was removed irregularly from the irradiated surface. Fragility of the outer acicular layer as well as the shock on the surface, because of high laser power, are mainly the reasons for irregular removal of the layer.

\section{CONCLUSIONS}

Microstructures, like microchannels and microchambers, were successfully patterned in the anodic oxide film of aluminium, with the help of laser beam, by increasing the absorption properties of the film. The main conclusions of this study are as follows:

1. Hydrothermal pore-sealing of the porous anodic oxide film significantly increases the absorbance properties of the film.

2. Colouring of the porous anodic oxide film by impregnating the organic dyestuff in the porous film, prior to hydrothermal pore-sealing of the film, further enhanced the absorption properties of the film, especially in the visible region.

3 . The crystalline hydroxide layers formed on the film surface, during hydrothermal pore-sealing, can be selectively removed from the film surface by using low power laser beam. Various types of microstructures with depth about $1 \mu \mathrm{m}$ can be patterned on the film surface by scanning the laser beam over the surface.

4. Microstructures with several tens of micrometer depth can be patterned on the coloured and poresealed anodic oxide film by increasing the thickness of the anodic oxide film and using higher laser power beam.

\section{ACKNOWLEDGEMENT}

The work was partially supported by a Grant-in-Aid from the Ministry of Education, Culture, Sports, Science and Technology; Japan. The authors would like to thank Dr. S. Fujita and Mr. K. Nagahara for their co-operation during the work.

\section{REFERENCES}

1. Y. Xia, J.A. Rogers, K.E. Paul and G.M. Whitesides, Chem. Rev., 99 (1999) 1823.

2. M. Geissler and Y. Xia, Advance Materials, 16 (2004) 1249
3. M.C. Gower, SPIE, 3343 (1998) 171.

4. A. Pique and D.B. Chrisey, Direct-write technologies for rapid prototyping applications, Academic Press, 2002.

5. S.Y. Chou, C. Keinel and J. Gu, Nature, 417 (2002) 835.

6. E. Makino and T. Shibata, J. Microelectromechanical System, 8 (1999) 177.

7. E.M. El-Giar, R.A. Said, G.E. Bridges and D.J. Thomson, J. Electrochem. Soc., 147 (2000) 586.

8. P. Mesquida and A. Stemmer, Microelectron. Eng., 61-62 (2002) 671.

9. W. Schindler, D. Hofmann and J. Kirschner, J. Electrochem. Soc., 148 (2001) C124.

10. Z. Kato, M. Sakairi and H. Takahashi, J. Electrochem. Soc., 148 (2001) C 790.

11. D.M. Kolb, R. Ullmann and J.C. Ziegler, Electrochem. Acta., 43 (1998) 2751.

12. T. Kikuchi, M. Sakairi and H. Takahashi, J. Electrochem. Soc., 150, (2003) C 567.

13. T. Kikuchi, M. Sakairi, H. Takahashi, Y. Abe and N. Katayama, J. Electrochem. Soc., 148, (2001) C 740.

14. T. Kikuchi, H. Takahashi and T. Maruko, Electrochim. Acta, 2006, In press (doi:10.1016/j.electacta.2006.08.040).

15. Y. Akiyama, T. Kikuchi, M. Ueda, M. Iida, M. Sakairi and H. Takahashi, Electrochim. Acta, 51 (2006), p. 4834.

16. M. Sakairi, M. Yamada and H. Takahashi, Electrochemical Society Proceedings, 19 (2004), p. 359.

17. N.I. Mukhurov, G.I. Efremov, I.F. Kotova, Technical Digest of IVMC'97, Kyongju, Korea, 17-21 Aug., 1997.

18. G.I. Efremov, N.I. Mukhurov, Proc. of ICECS'99, Pafos, Cyprus, 5-8 Sept., 1999.

19. G.I. fremov, N.I. Mukhrov, V.I. Kovalevsky, ASDAM 2000, The Third International EuroConference on Advanced Semiconductor Devices and Microsystems, Smolenice Castle, Slovakia, 16-18 Oct., 2000.

20. D. Ashkenasi, G. Muller, A. Rosenfeld, R. Stoian, I.V. Hertel, N.M. Bulgakova, E.E.B. Campbell, Appl. Phys. A 77 (2003) 223-228.

21. M. Sakairi, Z. Kato, S.Z. Chu, H. Takahashi, Y. Abe, and N. Katayama, Electrochemistry, 71, 11 (2003) 920.

22. H. Takahashi, ASM Handbook, ASM International, 13A (2003) 736.

23. M. Kohda, H. Takahashi, M. Nagayama, J. Met. Finish. Soc. Jpn, 33, 12 (1982) 614.

24. K. Wefers, Aluminium, 49, 8 (1973) 553, Aluminium, 49, 9 (1973) 622.

25. G. C. Wood and J. P. O'Sullivan, J. Electrochem. Soc., 116 (1969) 1351.

26. R. C. Spooner, Plating, 58 (1971) 449.

27. V. Lopez, M.J. Bartolome, E. Escudero, E. Otero, and J.A. Gonzales, Journal of The Electrochemical Society, 153, 3 (2006) B75-B82.

28.S.M. Moon, M. Sakairi, and H. Takahashi, J. Electrochem. Soc., 150, 10 (2003) B473-B480.

29. S.M. Moon, M. Sakairi, and H. Takahashi, J. Electrochem. Soc., 151, 7 (2004) B399-B405. 